\title{
Freezing Technology: Challenges and Prospects for Sustainable Development in Urban Infrastructure
}

\author{
Shunji Kanie ${ }^{1^{*}}$, Hao Zheng ${ }^{1}$ and Hiroshi Ogura ${ }^{2}$ \\ ${ }^{1}$ Faculty of Engineering, Hokkaido University, Sapporo, JAPAN \\ ${ }^{2}$ Seiken co., Osaka, JAPAN \\ ${ }^{*}$ Corresponding author: kanie@eng.hokudai.ac.jp
}

SUBMITTED 4 March 2019 REVISED 8 April 2019 ACCEPTED 11 April 2019

\begin{abstract}
Ground freezing has been broadly applied to construction and maintenance works of infrastructures because of its environmental friendliness. Since freezing technology represented by ground freezing can improve the strength of soil as well as its water-tightness, it becomes an essential technology for construction and maintenance of urban infrastructures where the use of space in the underground has already been highly integrated. In this paper, an overview of the freezing technology is introduced with some important characteristics of freezing soil for practical application. In addition, freezing technology is used for interesting works which could not be completed without freezing, and the state of the art in freezing technology is presented. A pipe-in-pipe, which the authors are developing, is an example to utilize the potential of frozen sand, and the effect of freezing is explained with experimental results.
\end{abstract}

KEYWORDS Ground freezing; Freezing technology; Frozen Soil; Frost

(c) The Author(s) 2018. This article is distributed under a Creative Commons Attribution-ShareAlike 4.0 International license

\section{INTRODUCTION}

With the increase in the development of our living environment, it becomes more important to update the existing infrastructures for the establishment of a sustainable lifestyle. Freezing technology is one of the essential key areas for improvement in urban infrastructures. Freezing technology represented by ground freezing method, which freezes up the original foundation, is frequently used at construction sites in an advanced urban area where population and industry have already been integrated. Recently, the number of applications of the ground freezing method is remarkably increasing in developed countries. The ground freezing method can drastically improve the strength of the soil and make the foundation watertight. In addition, the foundation is frozen up during the construction phase only and it is easily thawed after the construction. Then, it can be said that this method is environmentally friendly compared to other reinforcing works such as injection method, Consequently, construction of highway and subway networks at deep underground more than $60 \mathrm{~m}$ below the ground level could not have been completed without the freezing technology.

On the other hand, the effect of freezing on the surrounding structures and foundation should be seriously evaluated because the underground of the modernized city has already been occupied with various infrastructures. In advance of the construction, soil and hydraulic pressures due to freezing must be estimated accurately and carefully as well as the interactive displacements between the ground and the structure. Measurement and monitoring of those during the construction phase are obviously important with the sophisticated operation of freezing devices and apparatus. As numerical analyses, heat transfer analysis based on conduction and convection including latent heat is a must, and advection-diffusion analysis of thawed water may be required in a case as well as a thermos-mechanical computation for interactive behavior between foundation and structures. At a construction site where multiple existing structures are related to each other, on-site operation of freezing control is conducted by a feedback system between numerical forecast and real-time measurement. In the past 30 years, the strength of the frozen soil is discussed based on its uni-axial compressive strength only but nowadays the bending and shear strengths of the frozen soil are also taken into consideration for the evaluation of structural stability and safety. The freezing technology has been progressed day by day within both of software and hardware. In this paper, 
the authors review the versatility of using freezing technology as well as its technological issues.

\section{OVERVIEW OF GROUND FREEZING}

Ground freezing technology becomes frequently used at construction sites in urban areas. The major purposes of ground freezing methods are to improve the strength of the original soil and make the foundation watertight. The general procedure of freezing method is described as follows.

\subsection{The Procedure of Ground Freezing}

First, freezing pipes are installed into foundations at a predetermined interval as shown in Figure 1. Then, antifreeze known as brine or glycol solution starts to circulate in the pipe network to freeze the surrounding soil around the pipes. The pore water included in the soil becomes gradually frozen up into the shape of the column as a growing tree accumulates its growth rings in the radiation direction. Each column finally overlaps each other and a continuous frozen wall is built.

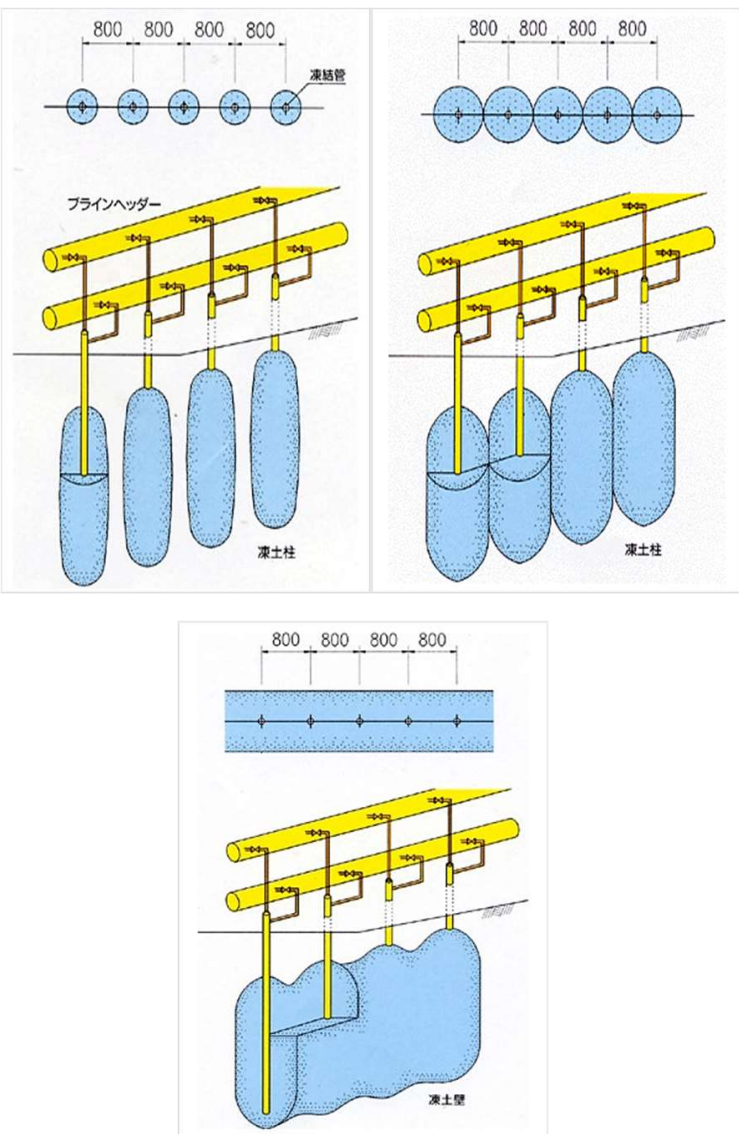

Figure 1. Freezing procedure of ground (SEIKEN co., 2018)

\subsection{Characteristics of Frozen Soil}

The strength of soil can be drastically improved by freezing. The strength of the soil is temperature dependent but the uni-axial strength becomes 4,000 to $12,000 \mathrm{kN} / \mathrm{m}^{2}$ at $-10^{\circ} \mathrm{C}$ even if its original unfrozen condition is soft. Figure 2 shows a typical relationship between uni-axial strength and temperature for fine sand and clay. At the same time, the salinity of pore water is another important factor for the strength of frozen soil and Figure 3 illustrate the effect of salinity on the uni-axial strength. If the construction site is close to a shoreline, the salinity of pore water is almost the same as that of seawater and it becomes hard to expect efficient hardening. When the salinity of pore water is as low as fresh water and the foundation consists of fine sand, on the contrary, the uni-axial strength is significantly improved. The typical design strength of frozen soil is summarized in Table 1.

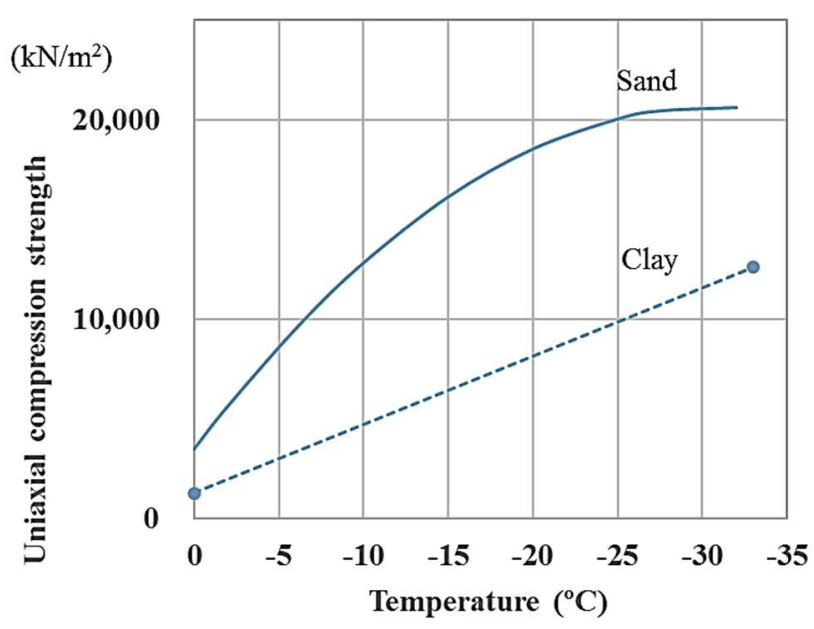

Figure 2. Relations between uni-axial strength and temperature (SEIKEN co., Ltd, 2018)

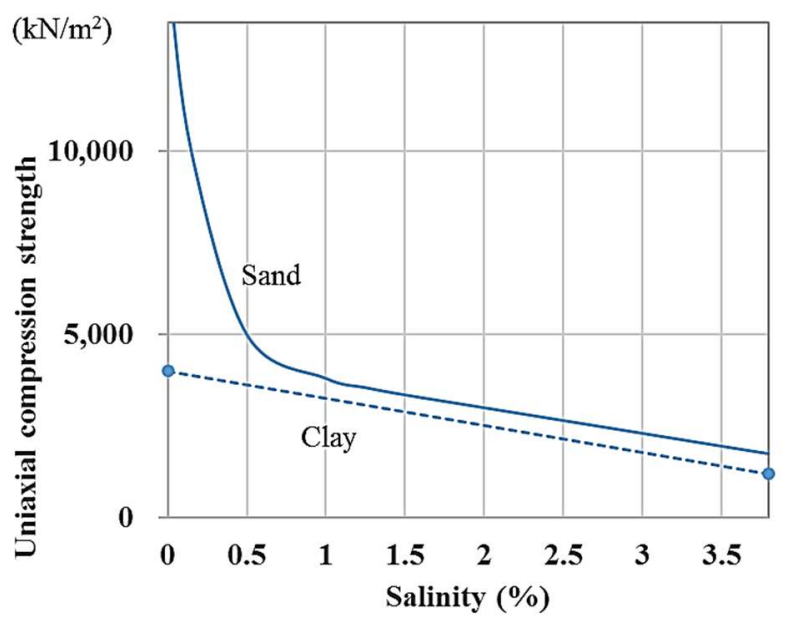

Figure 3. Relations between uni-axial strength and salinity (SEIKEN co., 2018) 
Table 1. The typical design strength of frozen soil at -10 degrees in Celcius

\begin{tabular}{lll}
\hline Strength $\left(\mathrm{kN} / \mathrm{m}^{2}\right)$ & Sand & Clay \\
\hline Compression & 3,000 & 4,500 \\
Shearing & 1,500 & 1,800 \\
Bending & 1,800 & 2,700 \\
\hline
\end{tabular}

\subsection{Frost Heave Evaluation}

One of the interesting phenomena during the freezing phase is frost heave which causes a volumetric change in the soil. The volumetric change is caused by two reasons. One of those is inflation due to in-situ freezing of pore water in the soil. When pore water freezes in soil, it inflates by $9 \%$ of the volume of water. Another reason is water migration due to ice lens formation. Ice lens is an ice layer formed in the transverse direction to heat flow by ice segregation which promotes water migration to ice lens. Since the volumetric change in soil may cause additional pressure on surrounding structures, careful consideration is necessary for the advance of execution of ground freezing.

In the case of sand with high permeability, the volumetric change is caused by in-situ freezing of pore water. At the same time, an increase in water pressure due to inflation promotes drainage from the unfrozen portion, and frost heave rarely happens. In the case of silt or clay with low permeability, on the other hand, the volumetric change is caused by the combined effect of in-situ freezing and water migration with ice lens formation. Then, frost heave should be carefully evaluated.

Figure 4 shows an experimental device for frost heave. A cylindrical specimen of soil is set in a vertical direction and is frozen from the top to the bottom. During the freezing phase, the specimen is fully saturated and water freely migrates from the bottom in both directions for drainage and absorption. The confining pressure to the specimen is given by a weight put at the top of the specimen. While the freezing front moves down in the specimen, frost heave occurs due to the ice-lens formation and the height of the specimen becomes larger than the original height as Figure 5 shows.

For the evaluation of frost heave, the Japanese Geotechnical Standard endorses the following equation known as Takashi's equation (Equation 1).

$$
\xi=\xi_{0}+\frac{\sigma_{0}}{\sigma}\left(1+\sqrt{\frac{U_{0}}{U}}\right)
$$

Here, $\xi$ is frost heave ratio, which is defined as the ratio of inflated volume to the initial volume of the specimen; $\sigma$ is the constraining effective stress in the freezing direction, and $U$ is the freezing rate which is the velocity of the advancement of the freezing front into the unfrozen portion. The dimension of freezing rate $U$ is $\mathrm{m} / \mathrm{s} . \xi_{0}, \sigma_{0}$ and $U_{0}$ are constants standing for the material properties of soil obtained by an experiment regulated by Japanese Geotechnical Standard (JGS 0171-2003) (Japanese Geotechnical Society, 2003).

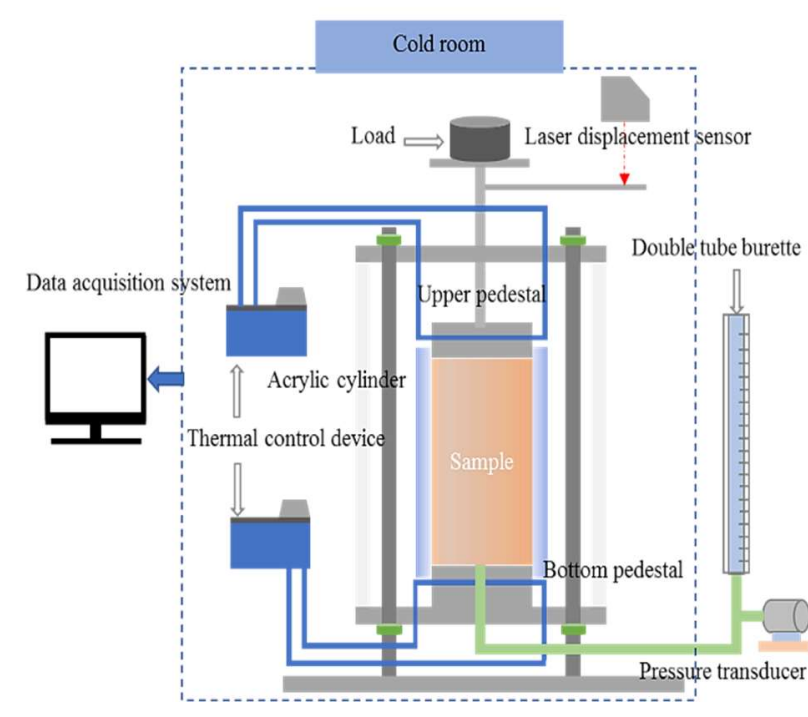

Figure 4. Experimental device for frost heave (Zheng and Kanie, 2017)

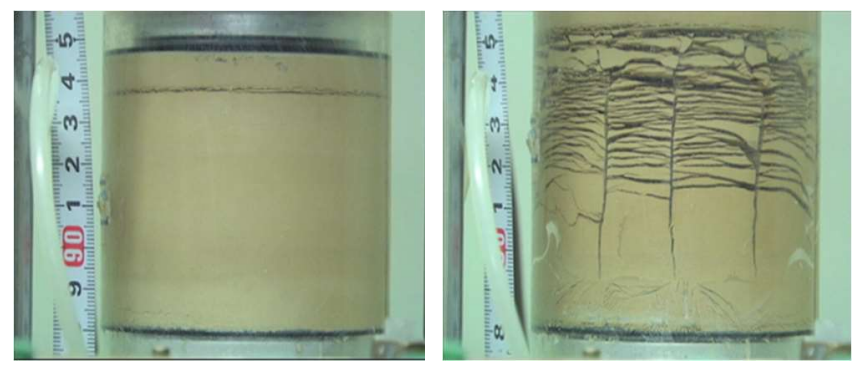

Figure 5. Comparison of the specimen before and after freezing

Takashi's equation was established based on numerous uni-axial frost heave experiments and it implies important characteristics of frost heave as a physical phenomenon. If the confining pressure $\sigma$ is large, the frost heave ratio $\xi$ is small. Similarly, when the freezing rate $U$ is fast, the frost heave ratio $\xi$ also becomes small because in-situ freezing of pore water is completed before the water migration due to segregation of ice-lens occurs.

In order to control the frost heave and its pressure, it is necessary to operate the freezing process appropriately corresponding to the material properties 
of soil. Therefore, heat transfer analysis including water migration is essential in advance as well as realtime monitoring of temperature distribution in the foundation during the execution of ground freezing.

\section{APPLICATION OF FREEZING TECHNOLOGY}

At the beginning of its technological history, the ground freezing method was mainly used for the development of mines and oil wells in the $19^{\text {th }}$ century. Recently, however, it has been adopted in urban areas of the modernized city and the application examples are concentrating in the cities of developed countries. The total number of constructions with the ground freezing method in Japan is more than 500 during the past 50 years and the total volume of frozen soil is almost $500,000 \mathrm{~m}^{3}$ only in Japan. The authors studied application examples in the world except for Japan, and the result is tabulated in Table 2 . It shows the locations of construction sites of ground freezing with the contractors in nationality.

The depth of construction at the early stage in mine and oil well was as deep as more than several hundred meters, but the major part of current applications is located within $100 \mathrm{~m}$ below from the ground level (GEOFROST AS, 1988; Rojo and Novillo, 1988; Haß, Jordan and Jessberger, 1994; Sopko and Braun, 2000; Taisei Coorporation, 2006; Hofstetter, Scholz and Heidkamp, 2007; Max Bögl, 2007; RKK-SoilFreeze Technologies, 2007a; Metropolitan Expressway Company Limited, 2011). It means that the freezing method has become more familiar and closer to our everyday life than ever.

Figure 6 shows the depths of construction in Europe, North America and others as well as Japan. Applications at deep underground more than $200 \mathrm{~m}$ were adopted almost for development of mines and oil wells. In Japan, on the contrary, the depths of application are concentrated within $60 \mathrm{~m}$ from the surface. In urban areas like Tokyo metropolitan area, newly built highway and subway networks are located deep underground where the ownership of land is never infringed. When construction work is conducted in deep underground near shoreline like Tokyo, all the structures including temporary works should resist against huge earth pressure as well as water pressure even in the construction phase. Ground freezing is one of the most competitive choices for those construction works because the strength of the soil is drastically improved and water tightness is ensured environmentally friendly. This is thought as the reason why ground freezing is commonly used in Japan. The number of applications has been still increased these days.

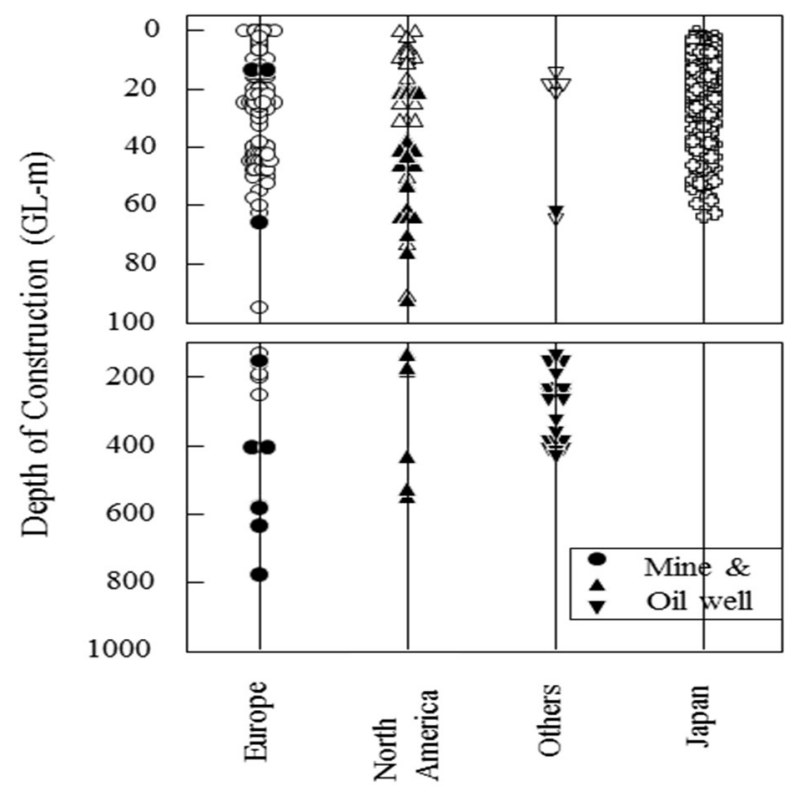

Figure 6. Depth of construction in the world 
Table 2. Ground freezing: Locations and Co ntractors in Nationality except for Japan

\begin{tabular}{|c|c|c|c|c|c|c|c|c|c|c|c|c|c|c|c|c|c|c|c|c|}
\hline & & & \multicolumn{17}{|c|}{ Nationality of Contractors } & \multirow[b]{3}{*}{ 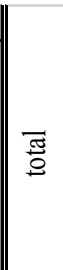 } \\
\hline & & & \multicolumn{11}{|c|}{ Europe } & \multicolumn{2}{|c|}{ Nth America } & \multicolumn{2}{|c|}{ Asia } & \multirow[b]{2}{*}{ 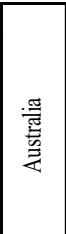 } & \multirow{2}{*}{ 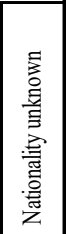 } & \\
\hline & & & 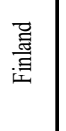 & 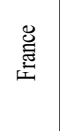 & $\begin{array}{l}\text { 窟 } \\
\text { 密 }\end{array}$ & 焉 & 突 & $\begin{array}{l}\text { 명 } \\
\text { 임 }\end{array}$ & 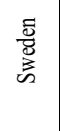 & 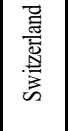 & $\begin{array}{l}\text { 䍃 } \\
\text { 至 }\end{array}$ & 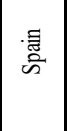 & $\begin{array}{l}\text { 䔍 } \\
\text { 总 } \\
\text { 至 }\end{array}$ & 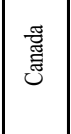 & 艿 & 苟 & 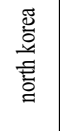 & & & \\
\hline \multicolumn{3}{|c|}{$\begin{array}{c}\text { Number of contractors } \\
\text { of freezing method }\end{array}$} & 2 & 1 & 5 & 2 & 1 & 1 & 1 & 2 & 1 & 1 & 1 & 1 & 6 & & 1 & 1 & & 27 \\
\hline \multirow{23}{*}{ 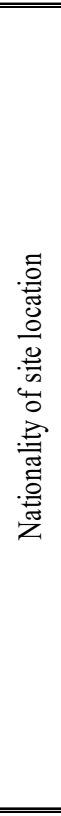 } & \multirow{15}{*}{ 气ั } & Australia & & & 3 & & & & & & & & & & & & & & & $\overline{3}$ \\
\hline & & \begin{tabular}{|l|} 
Belgium \\
\end{tabular} & & & 2 & & & & & & & & 2 & & & & & & & 4 \\
\hline & & Denmark & & 9 & & & & & & & & & & & & & & & 1 & 10 \\
\hline & & Finland & 3 & & & & & & & & & & & & & & & & & 3 \\
\hline & & France & & & & 2 & & & & & & & & & & & & & 5 & 7 \\
\hline & & Germany & & & 24 & & & 1 & & & & & & & & & & & 3 & 28 \\
\hline & & \begin{tabular}{|l|} 
Netherlands \\
\end{tabular} & & & 27 & & & & & & & & & & & & & & & 27 \\
\hline & & Italy & & & & 11 & & & & 2 & & & & & & & & & 1 & 14 \\
\hline & & \begin{tabular}{|l} 
Norway \\
\end{tabular} & & & & & 16 & & & & & & & & & & & & 1 & 17 \\
\hline & & \begin{tabular}{|l} 
Poland \\
\end{tabular} & & & & & & 2 & & & & & & & & & & & & 2 \\
\hline & & \begin{tabular}{|l|} 
Sweden \\
\end{tabular} & 1 & & & & 8 & & 1 & & & & & & & & & & & 10 \\
\hline & & \begin{tabular}{|l|} 
Switzerland \\
\end{tabular} & & & 3 & & & & & 4 & & & & & & & & & 1 & 8 \\
\hline & & \begin{tabular}{|l|} 
Russia \\
\end{tabular} & & & & & & & & & 19 & & & & & & & & & 19 \\
\hline & & Spain & & & & & & & & & & 5 & & & & & & & & 5 \\
\hline & & England & & & & & & & & & & & 9 & & & & & & & 9 \\
\hline & \multirow{2}{*}{ 专密 } & Canada & & & 3 & & & & & & & & 1 & 10 & 2 & & & & 1 & 17 \\
\hline & & USA & & & 15 & & & & & & & & & & 52 & & & & & 67 \\
\hline & \multirow{3}{*}{ 畓 } & Bangladesh & & & & & & & & & & & & & & & 2 & & & 2 \\
\hline & & China & & & & & 1 & & & 3 & & & & & & 26 & & & & 30 \\
\hline & & \begin{tabular}{|l|} 
Mongolia \\
\end{tabular} & & & & & & & & & & & & & & 1 & & & & 1 \\
\hline & \multicolumn{2}{|c|}{\begin{tabular}{|l} 
Australia \\
\end{tabular}} & & & & & & & & & & & & & & & & 1 & & 1 \\
\hline & \multicolumn{2}{|c|}{\begin{tabular}{|l} 
Brazil \\
\end{tabular}} & & & 1 & & & & & & & & & & & & & & & 1 \\
\hline & \multicolumn{2}{|c|}{\begin{tabular}{|l} 
South Africa \\
\end{tabular}} & & & & & & & & 1 & & & & & & & & & & 1 \\
\hline & & total & (4! & 99 & 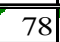 & 13 & 25 & 3 & 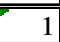 & 10 & 19 & 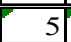 & 12 & 10 & 54 & 27 & 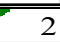 & |1 & 13 & 286 \\
\hline
\end{tabular}

Figure 7 is a picture of the junction constructed in the downtown area of Tokyo to connect the overhead viaduct with the underground expressway. Since the underground expressway is located at about $60 \mathrm{~m}$ below from the surface, vehicles spiral up within this junction more than $70 \mathrm{~m}$ at most in the vertical direction. The underground expressway is part of metropolitan expressway system and the continuous length of the underground tunnel reaches up to 18.2 $\mathrm{km}$ with many junctions. Figure 8 is a conceptual view of the tunnel, and the top roof connecting two tunnels were reinforced by the ground freezing method to excavate between the tunnels. Ground freezing technology was adopted in various situations in the construction phase and the current expressway network in the metropolitan area could not have been completed without ground freezing technology.

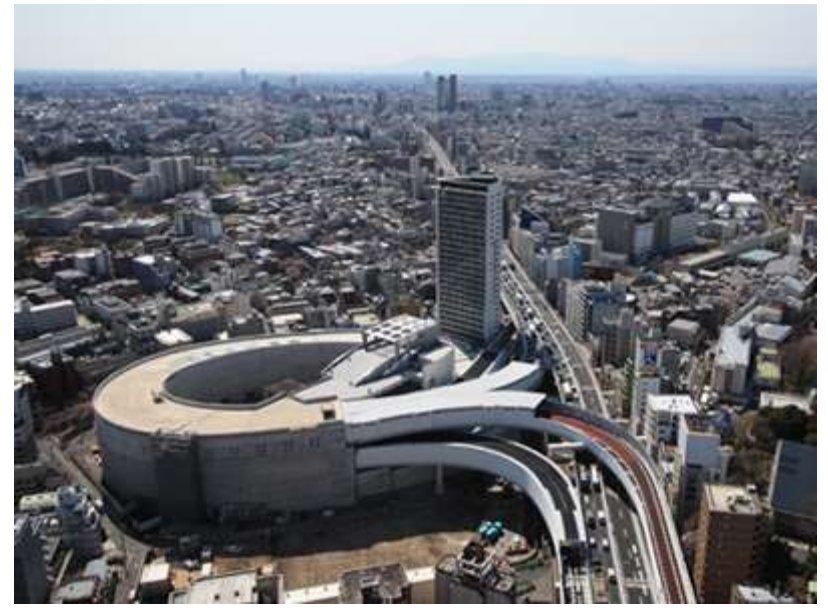

Figure 7. A bird's-eye view of a junction connecting viaduct with underground expressway in Tokyo (Metropolitan Expressway Company Limited. HP, 2011) 


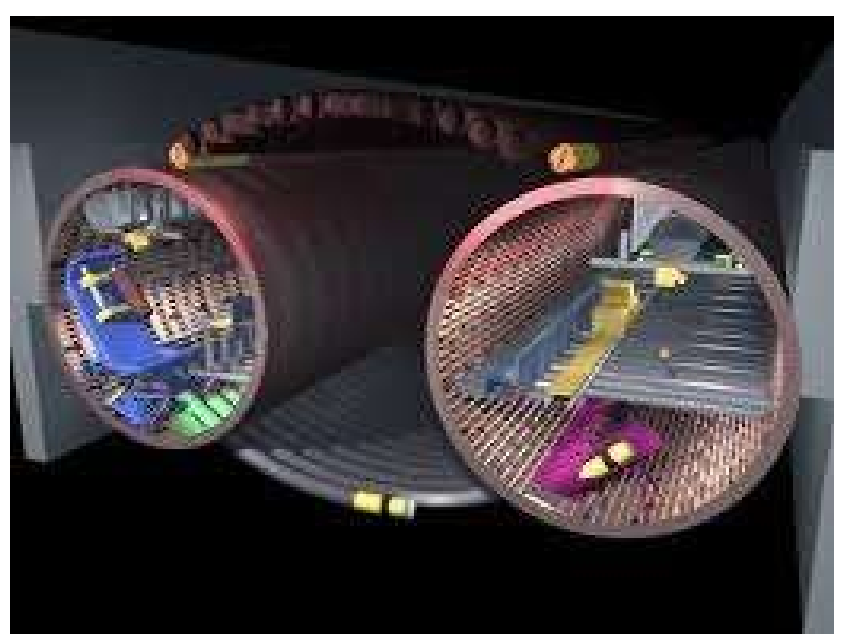

Figure 8. Conceptual view of the underground expressway (Taisei Corporation, 2006)

\section{APPLICATION OF FREEZING METHOD}

The freezing method has been widely adopted for various construction sites. Among those, the purposes of application can be classified into 7 categories such as; (i) Construction of vertical shaft, (ii) Strengthening around TBM (Tunneling Boring Machine) and shield machine, (iii) Strengthening for NATM (New Austrian Tunnelling Method) tunnelling, (iv) Repairing of underground pipes and culverts, (v) Prevention of settlement or deformation of existing structures, (vi) Removal of contaminated foundation, and (vii) Others.

In Europe and Japan, the freezing method is mainly applied for (ii) and (iii), constructions of tunneling including TBM and shield. In the United States of America, on the other hand, more than $50 \%$ of constructions with the freezing method are categorized into (i) Construction of vertical shaft because many mining sites had been developed in the past with freezing method. At the same time, in Europe and USA, (vi) Removal of the contaminated foundation is a common reason for application of the freezing method, and the ratio of (vi) to whole becomes $4 \%$ and $12 \%$ respectively. Here, several examples of application are briefly reviewed.

\subsection{Prevention of Settlement and Deformation}

If excavation may cause differential settlement of existing buildings in the vicinity, the freezing method could be adopted as a potent auxiliary method of the excavation. In downtown Boston, USA, a road tunnel was planned to be built with NATM just under existing buildings (Russia Building and Graphic Arts) as shown in Figure 9. Before the tunneling passes through the underground just below those buildings, 180 freezing pipes were installed into the foundation to secure the water tightness of the tunnel and to prevent the deformation of clay layer from the excavation. In this case, securing enough strength of soil was important and the temperature of antifreeze was set at $-15^{\circ} \mathrm{C}$ that is lower than the usual temperature for freezing. On the other hand, keeping enough strength of soil at a lower temperature may cause some more additional frost heave. Then, jacks were inserted under the footing of building to absorb the additional deformation.

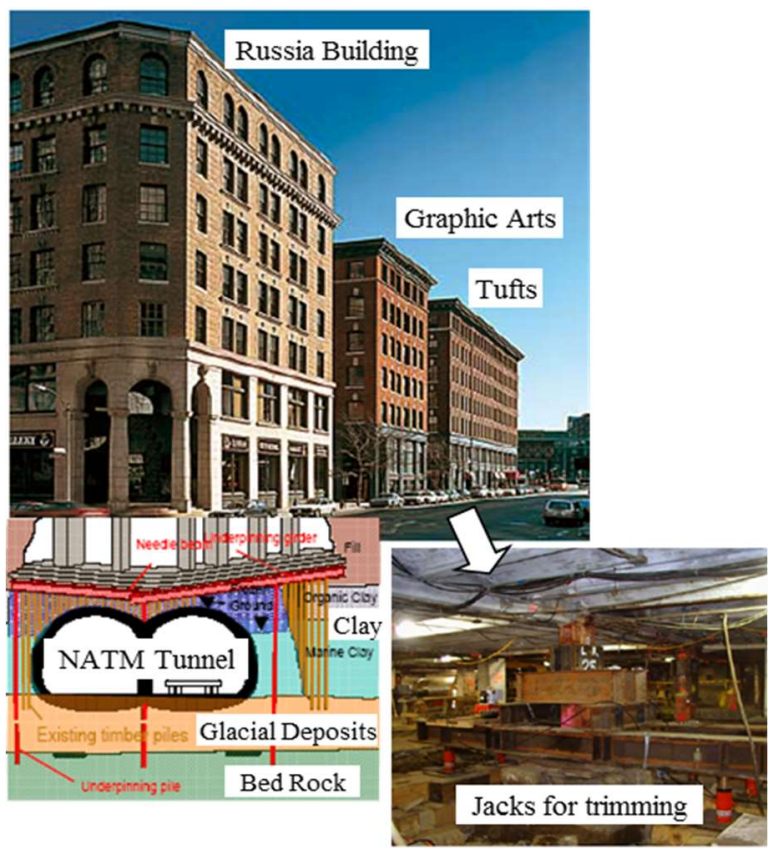

Figure 9. Prevention of deformation in Boston, USA (Mueser Rutledge Consulting Engineers, 2007)

\subsection{Repair of the Old Pipe}

In an industrial area in southern Germany, a part of the pipeline network was broken underground. The pipe was made of precast concrete with a diameter of 400 $\mathrm{mm}$. Then, it was decided to excavate from the surface, but three pipelines were installed just above the broken pipe. Therefore, the repairing work should have done with keeping those three pipes in service. The freezing method was adopted to resist against earth pressure acting on the side wall of excavation and to hold the sound three pipes at their original position as Figure 10 shows (Orth, 1988). The vertical freezing pipes promoted freezing of soil so firmly that the frozen wall surrounding the excavation had enough strength to support the three pipes in the air. In this case, the freezing wall was built within two days and the repairing work was successfully completed. Ground freezing contributes to shortening the construction period as well. 

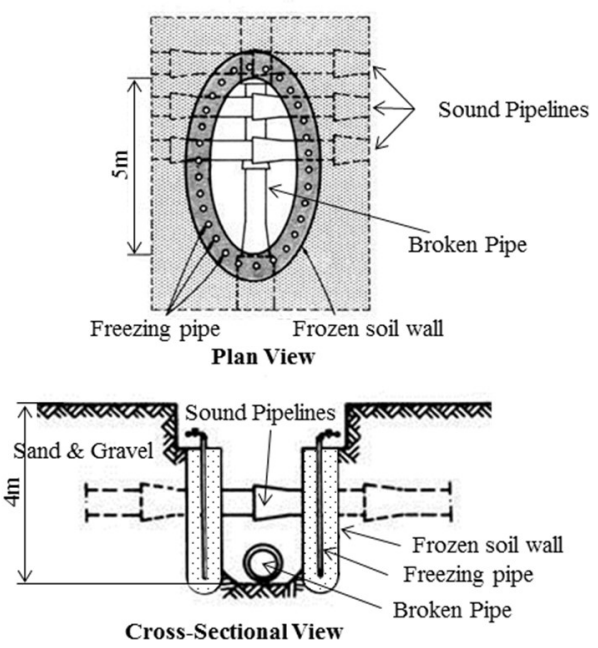

Figure 10. Repairing of old pipeline in southern Germany (Orth, 1988).

\subsection{Removal of Contaminated Foundation}

The last example introduced here is the removal of contaminated foundation. As mentioned earlier, ground freezing is frequently used in Europe and North America to remove contaminated foundation because the frozen wall can restrain the diffusion of contamination object due to the water tightness (MSE Technology Application, 1998). Figure 11 shows pictures of the removal of contaminated soil with hydrocarbon in a transformer substation for electricity in USA (RKK-SoilFreeze Technologies, 2007b). In this project, excavation had started without any protection against diffusion. However, the foundation consisted of sand and gravel with high permeability and the contamination object was diffused over a quite wide area with the flow of groundwater. A frozen wall was built to enclose the contaminated foundation and to prevent further diffusion from the site.
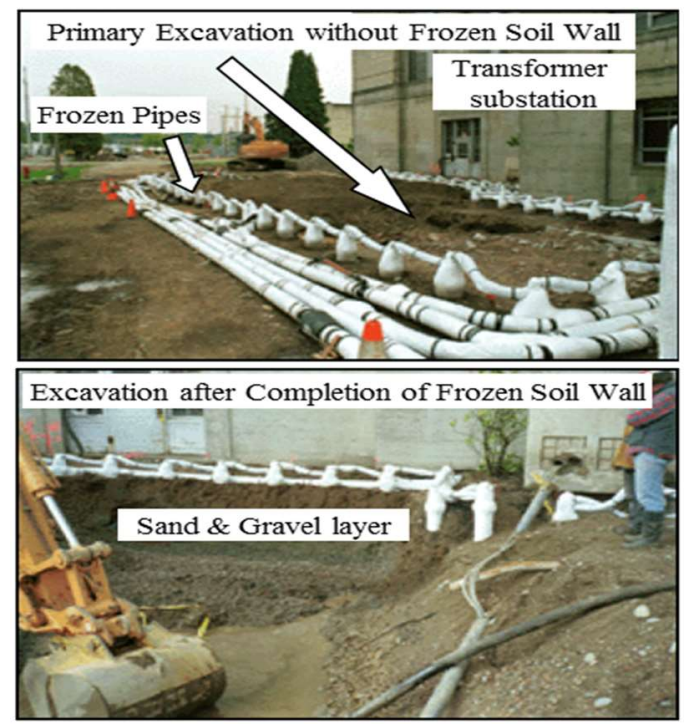

Figure 11. Excavation for removal of contaminated soil

\subsection{Prospect in Practical Application}

The freezing method is not used only for strengthening or water-tightening of foundation. It has been used for various purposes because of its versatility. As evidence which shows the versatility of the method, soft and sticky soil was temporarily improved by freezing in order to secure the trafficability of heavy construction equipment (Maishman, Powers and Lunardini, 1988). In a northern European country, the surface of the lake was frozen up for provisional parking lots during Winter Olympic Games (GEOFROST AS, 1991). Freezing method is environmentally friendly and it can be adopted wider and more flexible in purpose than ever not only for the construction at deep underground.

\section{PRACTICAL USE OF FREEZING EFFECT}

Freezing drastically improves the strength of the soil. One of the ideas of using the freezing effect is the pipein-pipe, which the authors are currently developing. The pipe-in-pipe consists of double thin-walled pipes, and the core between the pipes is filled with a filling material. The pipe-in-pipe itself has been used as a structural member with high flexural rigidity by filling the core with ceramic. Riser pipe mounted on oil drilling rigs in the Arctic Ocean is a typical example of its application. The pipe-in-pipe, here introduced, is filled with granular material such as sand instead of ceramic (Kanie et al., 2015). The purpose of the core material is not to increase the flexural rigidity but to transmit stress between double pipes within the section and to prevent local buckling known as Brazier effect as shown in Figure 12. Figure 13 shows the crosssectional view of the pipe-in-pipe. In order to imagine the effect of the core material, Figure 14 explains the effect. If a straw is bent, it is broken like the left picture. However, if granular sugar is filled into the straw, it becomes able to bend smoothly without any local failure as the right figure shows (Hayashi, Terada and Kanie, 2014). If it is adopted as a natural gas pipeline in permafrost, the temperature of the gas is preferably chilled under $0^{\circ} \mathrm{C}$ because the temperature effect on the surrounding foundation is minimized to prevent thawing of permafrost. At the same time, the chilled gas freezes the saturated sand filled in the core and enhances the flexibility and ductility of the pipe. The authors investigated its behaviors and established a numerical model for evaluation. 

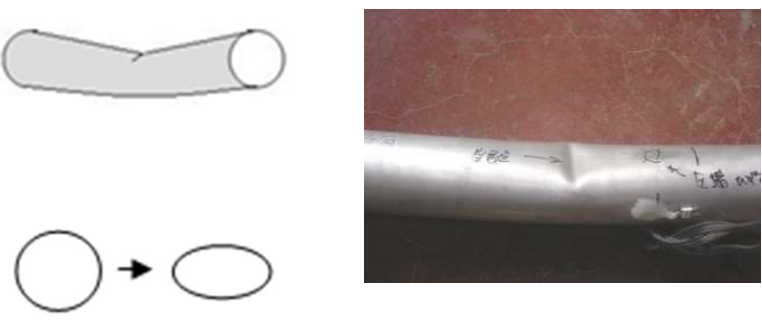

(a) Ovalization

(b) Failure of hollow pipe

Figure 12. Failure by Brazier effect

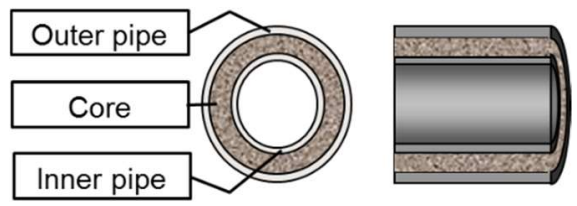

Figure 13. A cross-sectional view of Pipe-in-pipe

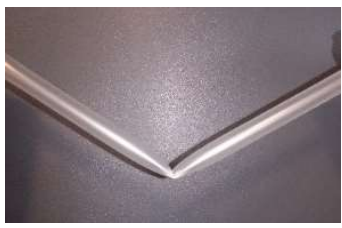

(a) Without sugar

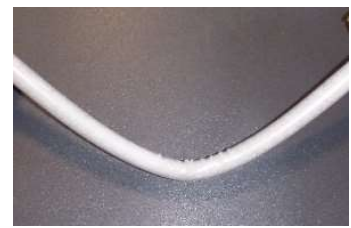

(b) Filled with sugar
Figure 14. Effect of filling material

The authors carried out indoor experiments to confirm the effect of freezing. All the pipes used in the experiment were made of aluminum alloy. Figure 15 shows the comparison of bending behaviors of singlewalled pipes. In the case of a hollow single-walled pipe, it is easily broken by Brazier effect like the left picture shows. However, if the pipe is filled with frozen sand, it can bend smoothly without local failure as shown in the right pictures. Figure 16 also shows the comparison of bending behaviors of the pipe-in-pipe with different diameters of inner pipes. As shown in those pictures, the bending behaviors of pipe-in-pipes are significantly improved.

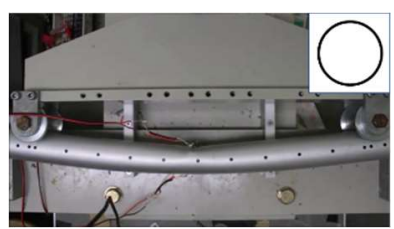

(a) Hollow pipe

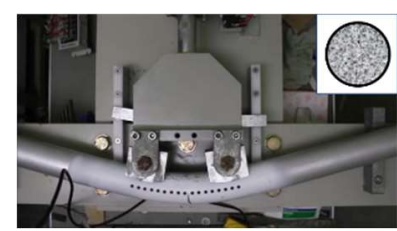

(b) Filled with frozen sand
Figure 15. Comparison of critical curvatures of single-walled pipes

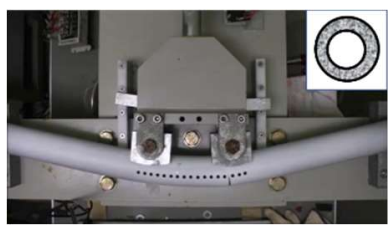

(a) $\phi 30 \mathrm{~mm}$ of the inner pipe

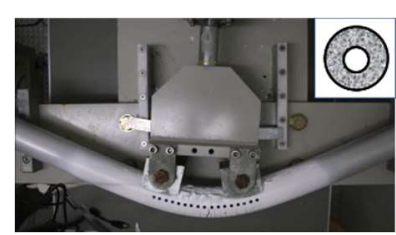

(b) $\phi 20 \mathrm{~mm}$ of the inner pipe
Figure 16. Comparison of critical curvatures of pipe-in-pipes filled with frozen sand (Diameters of outer pipes are the same as $50 \mathrm{~mm}$ )

Figure 17 illustrates the relations between bending moment and bending curvature. When a hollow pipe was broken by Brazier effect, the critical bending curvature was about 0.0006 in strain. However, the critical bending curvature of the pipe-in-pipe with 50 $\mathrm{mm}$ of the outer pipe and $20 \mathrm{~mm}$ of inner pipe reached to 0.004 and it is 7 times as much as that of a hollow pipe.

It was confirmed that the pipe-in-pipe can bend smoothly without local buckling by filling the core with granular frozen sand. The authors have already established a numerical model which can simulate the elasto-plastic behavior of the pipe-in-pipe consistently even under severe bending moment, and do believe that pipe-in-pipe is one of the most competitive ideas for pipeline material with high flexibility and ductility.

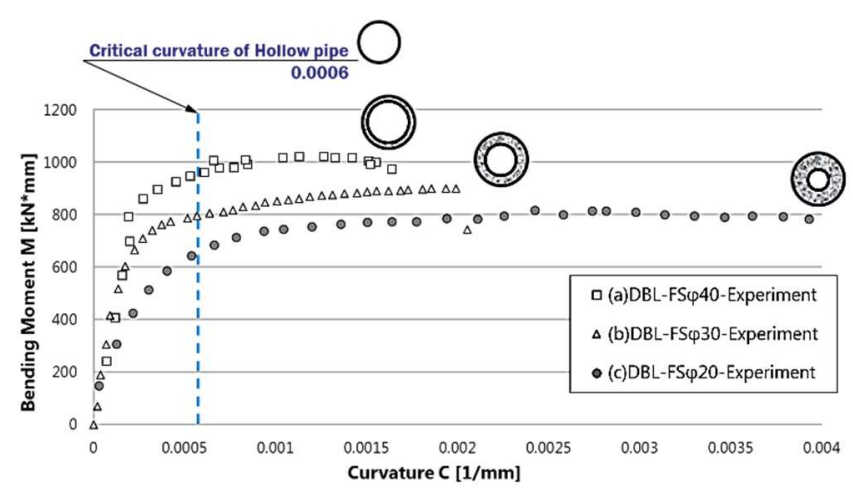

Figure 17. Relations between bending moment and bending curvature

\section{CONCLUSION}

Important is that the freezing method has excellent potential in its applicability with the low environmental impact on nature. In fully developed cities with highly integrated infrastructures in SouthEast Asia such as Hong Kong, Singapore or Jakarta for example, the needs for freezing technology would be 
increasing promptly. In addition, freezing can enlarge the possibility of better performance of the material property. In our laboratory, a pipe-in-pipe, double thin walled pipe filled with granular material between the gap, has been developed to exert high flexibility and fracture toughness of the material without failure.

We believe that freezing technology has more possibilities to contribute the sustainable development. At the same time, by scrutinizing this physical phenomenon more scientifically, civil engineering could offer various technological solutions environmentally friendly than ever.

\section{REFERENCES}

GEOFROST AS (1988) The Obbola Bridge. Available at: http://privat.bluezone.no/geo/frost/idex.htm.

GEOFROST AS (1991) Solvikbukta Froating Parking Area. Available at: http://privat.bluezone.no/geo/frost/idex.htm.

Haß, H., Jordan, P. and Jessberger, H. L. (1994) 'Use of artificial ground freezing in three sections of the Düsseldorf subway', Ground Freezing 94 ISGF, Proceedings.

Hayashi, A., Terada, Y. and Kanie, S. (2014) 'Development of pipe-in-pipe filled with granular material for flexible and ductile bending performance', Procedia Engineering. Elsevier, 95, pp. 232-240.

Hofstetter, C., Scholz, M. and Heidkamp (2007) Settlement Predictions and Surveillance During the Enlargement of the Metrostation Marienplatz in Munich. Available at: http://eurotun.tuwien.ac.at.

Japanese Geotechnical Society (2003) Test Method for Frost Heave Predictions of Soils. doi: JGS 0171-2003.

Kanie, S. et al. (2015) 'Numerical Analysis of Pipe-inPipe Filled with Various Materials', in Pipelines 2015American Society of Civil Engineers.

Maishman, D., Powers, J. P. and Lunardini, V. J. (1988) 'Freezing a temporary roadway for transport of a 3000 ton dragline', in 5th International Symposium on Ground Freezing, Nottingham, pp. 351-357.
Max Bögl (2007) Museum Isle in Berlin, Ground freezing technology. Available at: http://www.maxboegl.de/boegldip/web/content.jsp?n odeId $=1106$.

Metropolitan Expressway Company Limited (2011) Metropolitan Expressway Company Limited. Available at: http://www.shutoko.jp/ss/techshutoko/jyusyou/jyu22.html.

MSE Technology Application (1998) Frozen soil barrier cost estimation. Available at: http://www.mseta.com/cleanup/scsp_home.html.

Orth, W. (1988) 'Two practical applications of soil freezing by liquid nitrogen', in 5th International Symposium on Ground Freezing,Nottingham, pp. 389394.

RKK-SoilFreeze Technologies (2007a) Canterbury Castle underpinning. Available at: http: //www.cryocell.com / CCU.html.

RKK-SoilFreeze Technologies (2007b) Remedial excavation at Shuffleton Substation. Available at: http://www.cryocell.com/RESS.html.

Rojo, I. J. and Novillo, A. (1988) 'Recent applications of soil freezing techniques in Spanish construction works', in 5th International Symposium on Ground Freezing, pp. 525-532.

SEIKEN co., L. (2018) Ground Freezing Method. Available at: https://www.seikenn.co.jp/business/freeze_ground/fe atures/index.html.

Sopko, J. A. and Braun, B. (2000) 'Investigative and remedial methods for breach in a frozen shaft', in Proc., Int. Symposium on Ground Freezing, Brussels.

Taisei Coorporation (2006) MungoBlobs. Available at: http://www.taisei.co.jp/MungoBlobs/712/118/dec0101 ,0.pdf.

Zheng, H. and Kanie, S. (2017) 'The application of Mixed Hybrid FEM in the frost heave prediction verified by FEM and indoor frost heave experiments', Cold Regions Science and Technology. Elsevier, 142, pp. 85-92. 
[This page is intentionally left blank] 